\title{
SWISS ROLL TECHNIQUE FOR GIANT JUVENILE FIBROADENOMAS: A REPORT OF TWO CASES
}

Mudasser Rehan ${ }^{1}$, Archana Shetty², Manjunath V3, Vijaya $C^{4}$

\section{HOW TO CITE THIS ARTICLE:}

Mudasser Rehan, Archana Shetty, Manjunath V, Vijaya C. "Swiss Roll Technique for Giant Juvenile

Fibroadenomas: A Report of Two Cases". Journal of Evolution of Medical and Dental Sciences 2014; Vol. 3, Issue 04, January 27; Page: 972-975, DOI: 10.14260/jemds/2014/1934

ABSTRACT: Cosmesis is an important consideration when making breast incisions, especially in young girls. Giant fibroadenomas can produce breast deformity \& should be excised. There are several techniques for excision of giant firoadenoma. In our technique, we remove them through cosmetically acceptable circumaerolar incision to maintain the shape \& symmetry of breast. We recommend swiss roll technique for the excision of giant fibroadenomas.

KEY WORDS: Giant fibroadenoma, Swiss roll technique, circumaerolar incision, cosmetic results, breast.

INTRODUCTION: For a variety of reasons, giant breast tumours continue to pose a challenge in diagnosis and management. These tumours are poorly understood because of their rarity and unpredictable behaviour. ${ }^{1}$ Fibroadenomas of $5 \mathrm{~cm}$ or more, called giant fibroadenomas, is an uncommon variant of fibroadenomas. Their rapid growth and large size, together with their rarity may present difficulties in the clinical approach and must be excised in all cases to exclude phyllodes tumors \& to prevent later deformity. We report two cases of giant fibroadenoma which were excised by swiss roll technique, with a good cosmesis result, in our Institution.

CASE REPORT/TECHNIQUE: The two cases of Giant fibroadenomas of the breast were in girls aged 16 \& 18 respectively. Both were diagnosed on history \& clinical examination, supported by ultrasound. FNAC done on both showed features of a benign fibroadenoma. The swiss roll technique of excision was performed under general anesthesia. Subsequent histopathological examination of the excised masses confirmed the diagnosis as fibroadenomas, in both the cases.

TECHNIQUE: A $4 \mathrm{~cm}$ circumaerolar incision was made for the giant fibroadenomas, one measuring $15 \mathrm{cms}$ across and the other $18 \mathrm{cms}$ across, depending upon the site of fibroadenoma. Breast skin was mobilized over each of the fibroadenomas using the index finger till it was completely free from the surrounding breast tissue. The lump was then grasped using towel clip and pulled up to the skin and a circumareolar incision was made into the fibroadenomas. Fig. 1: Lateral view of giant fibroadenoma - Right Breast]

The fibroadenomas was progressively incised \& rotated out of the incision till the entire swelling was taken in a swiss roll type fashion. [Fig. 2: Circumareolar incision, with complete excision of fibroadenoma by Swiss roll technique] The dead space after the removal of fibroadenoma was not obliterated as the cavity is left to heal spontaneously by seroma formation. The cavity was packed with Roller ribbon gauze and pressure was applied for 3-5 min, later again the cavity was inspected after removing the pack and if there are any bleeders they are cauterized using bipolar cautery. Homeostasis was secured. No suction drain was used. Wound is closed in two layers underlying 
subcutaneous layer by putting interrupted sutures with vicryl $3 / 0$, and skin with monocryl $3 / 0$ subcuticular stitch. Dynaplast pressure dressing was done, and it was applied for $48 \mathrm{hrs}$.

The excised mass was sent for histopathological examination, which confirmed the diagnosis of fibroadenoma. [Fig. 3: $\mathrm{H}$ and $\mathrm{E}$ stain, 10x showing fibroadenoma comprising of proliferating benign ducts]. This surgery was done as day care procedure.

Both the patients were followed up post operatively, and have minimal surgical scars with good cosmetic results

DISCUSSION: Breast development is one of the first obvious signs of puberty. Any variation in its normal progression often deserves attention. Virginal hypertrophy, giant fibroadenoma, and cystosarcoma phyllodes are the important differential diagnoses to be considered when one encounters a large breast mass. ${ }^{2}$

These tumors are believed to be closely related variants of a similar pathologic process They are characterized by proliferation of epithelial and connective tissue elements in varying proportions. The exact aetiology in not known. Hormonal influences are thought to be contributory. ${ }^{3}$

Fibroadenomas are hyperplasias arising from the terminal ductulo-lobular unit and adjacent tissue of the breast. Giant fibroadenoma, ( $\geq 5 \mathrm{~cm}$ in size) is an uncommon variant of fibroadenoma. It is characterized by massive and rapid enlargement of encapsulated breast mass.

They constitute 0.2 - 5\% of all fibroadenomas. In the 1950's breasts were amputed for this relatively nonthreatening condition 4 . Patients with giant fibroadenomas should be treated with the assumption that the lesion is benign, and therefore local excision is the treatment of choice. Giant fibroadenomas tend to shrink after cessation of lactation, so their removal must be delayed until the patient's hormonal status returns to normal. ${ }^{5}$ Large fibroadenomas seldom regress and may continue to grow.

Surgical removal by enucleation is still the treatment of choice. However, with time a lot many newer techniques have come into practice. Varying techniques in surgical extirpation have been described in order to optimize aesthetics and minimize distortion. The advent of new methods to remove benign breast disease is in its infancy stages ${ }^{6}$.Several surgical procedures have been designed to camouflage the scar, by placing the incision in a circum-areolar or submammary crease. ${ }^{7}$

Cosmesis is an important consideration when making breast incisions especially in young girls. In swiss role technique the tumor is removed in a shape of Swiss roll after complete enucleation, which was confirmed by observing tumor being freely moved within breast cavity. One alternate is to fragment the fibroadenoma in situ and then remove the fragments. However; there is obvious risk of leaving pieces back. ${ }^{4}$

By cutting the lesion in the shape of a Swiss roll, the mass can be removed in its entirety. As the breast skin is stretched, quite a large circumareolar incision can be made. This shrinks back to normal after removal of the fibroadenoma ${ }^{8}$.Swiss-roll operation thus allows large tumors like giant fibroadenomas to be removed through a cosmetically acceptable small circumareolar incision ${ }^{9}$. We have presented two such cases, operated with this technique, and have found it to be extremely acceptable for giant fibroadenomas in young females.

Newer techniques have been proposed for fibroadenomas, such as percutaneous excision or in situ cryoablation, which are less invasive, but they can be applied only to smaller fibroadenomas 10 . 
CONCLUSION: The giant fibroadenoma is commonly found between 20-25 year of age, which should be removed through cosmetically acceptable circumaerolar incision especially in unmarried young females. Swiss roll technique is simple, safe \& best technique having good cosmetic results \& performed as a day care surgery.

\section{REFERENCES:}

1. Arowolo O. A, Akinkuolie AA, Adisa A.O, Obonna GC, Olasode B J. Giant fibroadenoma presenting like fungating breast cancer in a Nigerian teenager African Health Sciences 2013; 13(1): 162 165.

2. Thuruthiyath N, Chandra Das P, Avabratha S, et al. Giant Fibroadenoma of Breast in an Adolescent Girl Oman Medical Journal (2012) Vol. 27, No. 4: 314-315 DOI 10. 5001/omj.2012.77.

3. S. H. Waqar, M Tariq Abdullah, Zafar Malik, M A Zahid. Case report. A giant fibroadenoma breast Ann. Pak. Inst. Med. Sci. 2009; 5(2): 126-127.

4. Soomro S.A, Memon SA, Mohammad N, Maher M. Swiss roll operation for giant fibroadenoma. J Ayub Med Coll Abbottabad. 2009 Jan-Mar; 21(1):76-8.

5. Greenberg, R, Skornick Y and Kaplan O. Management of breast fibroadenomas. Journal of General Internal Medicine 2004 September 13(9) 640 -645.

6. Sosin M, Feldman E. Giant juvenile fibroadenoma: a case and review of novel modalities in treatment. Breast Dis. 2012; 34(1):35-8. doi: 10.3233/BD-130342.

7. Rojananin S, Ratanawichitrasin A. Limited incision with plastic bag removal for a large fibroadenoma. Br J Surg. 2002 Jun; 89 (6):787-8.

8. Maharaj, D, Naraynsingh V. and Ramdas M. Management of Giant Fibroadenomas: A Case for Small Incisions for Large Tumors. The Breast Journal, 2003; 9: 141. doi: 10.1046/j.15244741.2003.09218.x.

9. Naraynsingh V, Maharaj D, Rampaul R. The ÒSwiss-roll Óperation for excision of giant fibroadenomas. Breast J 2012; 8:45Đ46.

10. Matz D, Kerivan L, Reintgen M. Breast Preservation in Women With Giant Juvenile Fibroadenoma Clinical Breast Cancer, Vol. (Article in press) 2012.

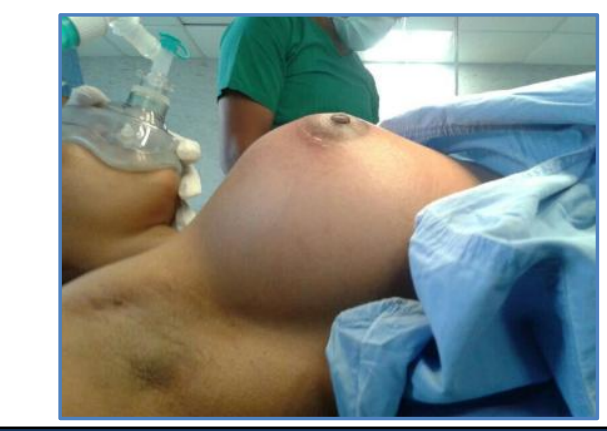

Fig. 1: Lateral view of giant fibroadenoma - Right Breast 


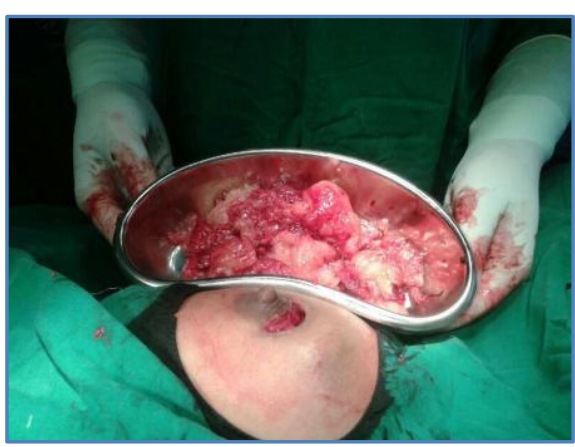

Fig. 2: Circumareolar incision, with complete excision of fibroadenoma by Swiss roll technique

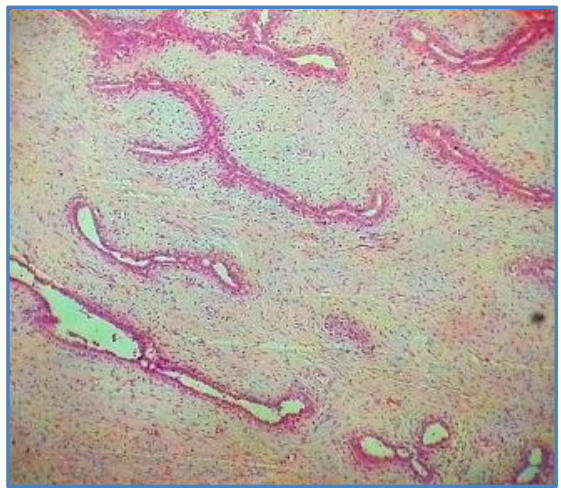

Fig. 3: H and E stain, 10x showing fibroadenoma comprising of proliferating benign ducts

\section{AUTHORS:}

1. Mudasser Rehan

2. Archana Shetty

3. Manjunath V.

4. Vijaya C.

\section{PARTICULARS OF CONTRIBUTORS:}

1. Assistant Professor, Department of Surgery, Sapthagiri Institute of Medical Sciences and Research Center, Bangalore.

2. Assistant Professor, Department of Surgery, Sapthagiri Institute of Medical Sciences and Research Center, Bangalore.

3. Assistant Professor, Department of Surgery, Sapthagiri Institute of Medical Sciences and Research Center, Bangalore.
4. Professor, Department of Surgery, Sapthagiri Institute of Medical Sciences and Research Center, Bangalore.

\section{NAME ADDRESS EMAIL ID OF THE CORRESPONDING AUTHOR:}

Dr. Archana Shetty,

Street No. 15,

Hesaraghatta Main Road,

Chikkasandra, Bangalore - 560090 .

Email - archanashetty2924@gmail.com

Date of Submission: 27/12/2013.

Date of Peer Review: 28/12/2013.

Date of Acceptance: 16/01/2014.

Date of Publishing: 23/01/2014. 